\title{
Transversus abdominis plane block with general anesthesia blunts the perioperative stress response in patients undergoing radical gastrectomy
}

\author{
Ruizhu Liu', Haiyan Qin², Meng Wang ${ }^{3}$, Kai Li $^{1 *}$ and Guoqing Zhao ${ }^{1 *}$ (D)
}

\begin{abstract}
Background: Surgical stress induces the release of neuroendocrine mediators and cytokines during perioperative period, which may have adverse effects on cancer patients. While the surgical stress responsse can be affected by anesthetic technique. Therefore, we designed this study to assess whether subcostal transversus abdominis plane (TAP) block can affect perioperative neuroendocrine stress response, postoperative analgesia and postoperative recovery in patients undergoing radical gastrectomy under general anesthesia.

Methods: Sixty-five patients were recruited. Patients randomly received general anesthesia (control group), or general anesthesia combined with TAP block ( $40 \mathrm{~mL}$ of $0.375 \%$ ropivacaine) (TAP group). The primary outcome was neuroendocrine levels including norepinephrine (NE), epinephrine (E), cortisol (Cor), glucose (Glu), interleukin (IL)-6 and IL-10 during $48 \mathrm{~h}$ after surgery. Secondary outcomes included pain score, hemodynamic variables and recovery characteristics.

Results: Data from 61 of 65 patients were analyzed. The levels of NE, E, Cor, and Glu were blunt by TAP block during perioperative period. The levels of IL-6 and IL-10 were significantly lower in TAP group than in control group. TAP block efficiently relieved postoperative acute pain up to $12 \mathrm{~h}$ postoperatively with more stable perioperative hemodynamics compared with control group.
\end{abstract}

Conclusions: Subcostal TAP block blunts perioperative stress response and provides efficient analgesia, with good hemodynamic stability and minimal adverse effects.

Keywords: Gastric cancer, Nerve block, Analgesia, Stress

\section{Background}

Gastric cancer is one of the most commonly diagnosed cancers around the world. Surgical resection is currently the mainstay of curative treatment for this cancer, which is recommended to maximize the probability of complete tumor clearance, reduce loco-regional recurrence, and improve long-term survival [1]. Transabdominal radical gastrectomy is an effective therapeutic strategy for malignant gastric disease. However, open gastrectomy causes severe pain in the incision of abdominal wall. Surgical trauma

\footnotetext{
* Correspondence: likai82@126.com; zhaogq65@126.com

1 Department of Anesthesiology, China-Japan Union Hospital of Jilin

University, No. 126 Xiantai Road, Changchun 130000, Jilin Province, China

Full list of author information is available at the end of the article
}

accompanied with considerable surgical pain is a key variable affecting the surgical stress response and prognosis [2]. The responses of patients towards surgical pain may result in unstable hemodynamics, and this excessive stress action is adverse for postoperative rehabilitation and long-term prognosis for patients with malignant tumor [3]. Thus, effective modulation of stress response may reduce the incidence of complications $[4,5]$.

Transversus abdominis plane (TAP) block, as an emerging regional anesthetic technique, can provide efficient analgesia by blocking the regulation of sensory nerve at the anterior abdominal wall [6], which can reduce opioid consumption, and lessen opioid-related side effects [7-9]. TAP block is given before the occurrence of noxious

(c) The Author(s). 2019 Open Access This article is distributed under the terms of the Creative Commons Attribution 4.0 International License (http://creativecommons.org/licenses/by/4.0/), which permits unrestricted use, distribution, and reproduction in any medium, provided you give appropriate credit to the original author(s) and the source, provide a link to the Creative Commons license, and indicate if changes were made. The Creative Commons Public Domain Dedication waiver (http://creativecommons.org/publicdomain/zero/1.0/) applies to the data made available in this article, unless otherwise stated. 
stimulation, which could relieve the postoperative pain by alleviating the pain of peripheral and central sensitization [10]. Recently, analgesic effect of TAP block has been widely studied, but the study associated with its efficiency on stress response that compared with general anesthesia is limited.

Subcostal, mid-axillary and lumbar triangle of Petit approaches are widely used in TAP block [11]. The bisubcostal approach is associated with wide block area of spread (T7-L1) [12, 13], and could provide a satisfactory analgesic plane for transabdominal gastrectomy. The current study was aimed to investigate the effects of subcostal TAP block on stress response and analgesic effect in patients undergoing open radial gastrectomy under general anesthesia.

\section{Methods}

\section{Patients and grouping}

Our study was approved by the Ethics Committee of ChinaJapan Union Hospital of Jilin University (2016ks008) and was in accordance with good clinical practice and the guiding principles of the Helsinki Declaration. The written informed consents were obtained from all patients. The trial was registered prior to patient enrollment at clinicaltrials. gov (NCT03035916, principal investigator: Guoqing Zhao, Ruizhu Liu, Kai Li, date of registration: 01/27/2017).

Patients meeting the following inclusion criteria were enrolled: patients who were scheduled for open radical gastrectomy; patients who had no contraindication to local anesthetic, and patients whose American Society of Anesthesiologists' (ASA) physical status I, II or III. Emergency patients and patients with preoperative infection, or patients with a history of immune disease, endocrine system disease, blood transfusion, or chemotherapy were excluded from this study.

Patients were randomly divided into two groups by a computerized random-number generator with 1:1 ratio for TAP group and control group. The pre-anesthetic interview was carried out by a single investigator to assess the eligibility of participants and to record the baseline data. Another anesthesiologist (not involved in study) who took the corresponding opaque envelope in the operating room performed the block and anesthesia induction, so he was unblinded to group allocation. A resident anesthetist who was blinded to randomization was responsible for collection of intraoperative data and blood. Postoperative data and blood were collected by another investigator who visited the participants at 1,6 , $12,24,48 \mathrm{~h}$ after surgery. All patients underwent surgery from the same operative team. The patients allocated to respective groups were administered as follows: TAP group: general anesthesia and ultrasonography-guided TAP block with $40 \mathrm{ml}$ of $0.375 \%$ ropivacaine; Control group: standard general anesthesia (no sham intervention for TAP block).

\section{Operation process}

No preoperative sedatives or analgesics were administered before the operation. Routine monitoring including electrocardiogram, invasive arterial blood pressure, pulse oximetry, and end-tidal carbon dioxide was established before anesthetic induction. All patients underwent standard general anesthesia induced by midazolam $0.02 \mathrm{mg} / \mathrm{kg}$ (Enhua Pharmaceutical Co., Ltd., Jiangsu, China), propofol 2.0-2.5 $\mathrm{mg} / \mathrm{kg}$ (Fresenius Kabi Deutschland, Germany), sufentanil $0.3 \mu \mathrm{g} / \mathrm{kg}$ (Yichang Humanwell Pharmaceutical Co., Ltd., Yichang, China), and cis-Atracurium $0.15 \mathrm{mg} / \mathrm{kg}$ (Hengrui Pharmaceutical Co., Ltd., Jiangsu, China). In order to maintain general anesthesia, intravenous and inhaled volatile anaesthetics of nitrous oxide, sevoflurane (Maruishi Pharmaceutical Co., Ltd., Japan), sufentanil, and cis-Atracurium were used. During the operation, the MAC value was maintained within $1.2-1.5 \%$ by regulating the inhalation concentration of nitrous oxide and sevoflurane. Tidal volume and rate were adjusted to maintain an end-tidal PCO2 of 30-40 $\mathrm{mmHg}$. When hemodynamic values increased more than $15 \%$ above pre-induction baseline values, an appropriate dose $(0-10 \mu \mathrm{g})$ of sufentanil was used to intervene. Heart rate $(\mathrm{HR})<40$ beats/min (bradycardia) was intervened with $0.5 \mathrm{mg}$ atropine, and mean arterial blood pressure (MAP) < $60 \mathrm{mmHg}$ (hypotension) was treated with $5 \mathrm{mg}$ ephedrine. The body temperature was maintained between $36^{\circ} \mathrm{C}$ and $37^{\circ} \mathrm{C}$ during the operation.

TAP block was administered after anesthesia induction. In the TAP group, TAP block was performed bilaterally under ultrasound (SonoSite Portable M-Turbo, Sonosite Inc., Bothwell, UT, USA) guidance at $30 \mathrm{~min}$ before the surgical incision. The probe was placed in the midline of abdomen below the xiphoid and moved right laterally along the subcostal margin to the anterior axillary line. After the probe identified the plane between the rectus and transverse abdominal muscles, a $100-\mathrm{mm}$, 20-G Stimuplex block needle was guided within the plane to the point just inferior to the right costal margin such that the tip laid between the obliquus internus abdominis and transversus abdominis within the neurovascular fascial plane. After aspiration, to exclude vascular puncture, $1 \mathrm{~mL}$ test dose was injected to determine the flow resistance and confirm needle tip placement within the fascial plane. Then, $10 \mathrm{~mL} 0.375 \%$ ropivacaine was multi-point injected in this plane laterally along the subcostal margin. The probe was moved back to the anterior axillary line, and another $10 \mathrm{~mL} 0.375 \%$ ropivacaine was injected through the needle inferior to the costal margin within the TAP using an identical technique, making this two injected drug a continuous plane under the costal margin, from the medial margin of the 
rectus abdominis muscle to anterior axillary line. The left side of TAP block was conducted with the identical technique.

After extubation, patients were transferred to the postanesthesia care unit (PACU), and all of them received morphine patient-controlled analgesia (PCA) with a standard dosing regimen: $2 \mathrm{~mL} / \mathrm{h}$ continuous infusion (a bolus of $1 \mathrm{~mL}$ with a lock-time of $15 \mathrm{~min}$ ) by using the electronics pump (Shanghai Bochuang, China).

\section{Postoperative detection}

The primary outcome was neuroendocrine mediators and cytokines at different time points of $48 \mathrm{~h}$ after operation. Venous blood samples were collected before anesthesia (baseline), immediately after surgery, and at 6, 24, and 48 $\mathrm{h}$ after surgery, and stored in pre-chilled tubes on ice and then centrifuged within $90 \mathrm{~min}$. The separated plasma was stored at $-80^{\circ} \mathrm{C}$. Glucose (Glu) level was measured immediately after venous blood was collected using glucometer (ACCU- CHEK Active, Inc.). Plasma levels of norepinephrine $(\mathrm{NE})$, epinephrine $(\mathrm{E}), \mathrm{C}$-reactive protein (CRP), cortisol (Cor), interleukin (IL)-6, and IL-10 were measured by micro enzyme-linked immunosorbent assays kits (R\&D system, Inc.,USA).

The second outcomes included pain scores, hemodynamic variables and recovery characteristics during the first 2 postoperative days. Pain scores included VAS scores at rest and during movement (cough or rotating the body) in the first 2 postoperative days. The MAP and HR were continuously measured and recorded before anesthesia, during induction, tracheal intubation, incision, immediately after tracheal extubation, as well as at 6,24 , and $48 \mathrm{~h}$ postoperatively. The other recorded observations included additional sufentanil consumption, postoperative opioid requirement, and recovery profiles (duration of PACU, side effects such as nausea, sedation, and vomiting, time of first flatus, and hospital stays). Sedation was assessed by Ramsay score (2-4: satisfactory sedation, $>4$ : excessive sedation). Additionally, discontinuing PACU was determined by a standard score test (= 10: PACU should be discontinued). The study processes are shown in Additional file 1: Figure S1.

The minimum detectable difference of plasma cortisol concentration was estimated immediately after surgery between two groups. The mean and SD values of plasma cortisol were as follows: $\mathrm{MTAP}=410 \mathrm{nmol} / \mathrm{L}$, MControl $=521 \mathrm{nmol} / \mathrm{L}, \quad \mathrm{STAP}=142 \mathrm{nmol} / \mathrm{L}$, and SControl $=$ $16.4 \mathrm{nmol} / \mathrm{L}$. Based on sample size analysis performed using PASS 11.0 (NCSS Statistical Software, Kaysville, UT), with $\alpha=0.05$ and $\beta=0.2$, a minimum sample of 25 cases in each group was required, respectively.

\section{Statistical analysis}

Statistical analyses were performed using SPSS 18.0 (Chicago, IL, USA). The normal distribution of data was evaluated using Shapiro-Wilk test. Data were expressed as mean $( \pm \mathrm{SD})$ or percentages of the total number of patients (\%). Comparisons of NE, E, Cor, Glu, cytokines, hemodynamic data, and VAS scores between groups were performed by repeated-measures analysis of variance. The differences for opioid consumption, time to first flatus, and time in PACU were analyzed using Student's $t$ test followed by 2-tailed Dunnett test. Categorical data were analyzed by using $X^{2}$ or Fisher exact test. $P$ value $<0.05$ was considered significant.

\section{Results}

Total 65 patients were enrolled from February 2017 to August 2017. According to the exclusion criteria, 4 patients were excluded, and data from 61 patients (30 in TAP group, 31 in control group) were finally analyzed. Baseline characteristics showed no significant difference between two groups (Table 1).

There were no significant differences for NE, E, and Cor values on baseline. Compared with control group, the NE and $\mathrm{E}$ values were significantly lower in the TAP group at 6 $h \quad\left(P_{N E}=0.001, P_{E}=0.010\right), 24 h \quad\left(P_{N E}=0.022, P_{E}<0.001\right)$ and $48 \mathrm{~h}$ postoperatively $\left(\mathrm{P}_{\mathrm{NE}}=0.001, \mathrm{P}_{\mathrm{E}}<0.001\right.$ ) (Fig. 1a, b). The Cor levels were significantly higher in the control group than in TAP at all time points postoperatively (Fig. 1c). Additionally, the levels of NE, E, and Cor were more stable in TAP group compared with that in control group. Moreover, in TAP group, levels of the three hormones returned to baseline values by $24 \mathrm{~h}$, whereas in the control group these parameters were significantly higher than the baseline values (Fig. 1). Glu levels did not differ between the two groups at baseline, but their levels were higher in the control group than in TAP group immediately after surgery, and at $6 \mathrm{~h}$ and $24 \mathrm{~h}$ postoperatively $(P<0.001)$ (Fig. $1 \mathrm{~d})$.

Plasma levels of IL- 6 and IL-10 were not different at baseline. In the control group, IL- 6 and IL-10 continued to increase even at $48 \mathrm{~h}$ postoperatively, whereas in TAP

Table 1 Demographic and perioperative characteristics by study group

\begin{tabular}{llll}
\hline Parameters & $\begin{array}{l}\text { Control group } \\
(n=31)\end{array}$ & $\begin{array}{l}\text { TAP group } \\
(n=30)\end{array}$ & P-value \\
\hline Age (yr) & $60.20 \pm 8.93$ & $58.95 \pm 8.24$ & 0.31 \\
Gender (M/F) & $23 / 8$ & $21 / 9$ & 0.75 \\
Weight (kg) & $65.90 \pm 8.63$ & $67.33 \pm 11.62$ & 0.42 \\
Height (cm) & $165.40 \pm 12.10$ & $168.90 \pm 12.37$ & 0.49 \\
ASA physical & $4 / 20 / 7$ & $5 / 19 / 6$ & 0.56 \\
status (I/I/III) & & & \\
$\begin{array}{l}\text { Duration of } \\
\text { anesthesia (min) }\end{array}$ & $235.25 \pm 42.14$ & $238.50 \pm 43.66$ & 0.79 \\
$\begin{array}{l}\text { Duration of } \\
\text { surgery (min) }\end{array}$ & $207.00 \pm 34.01$ & $195.83 \pm 34.76$ & 0.18 \\
\hline
\end{tabular}

Values are mean $\pm \mathrm{SD}$ or number

ASA American Society of Anesthesiologists 


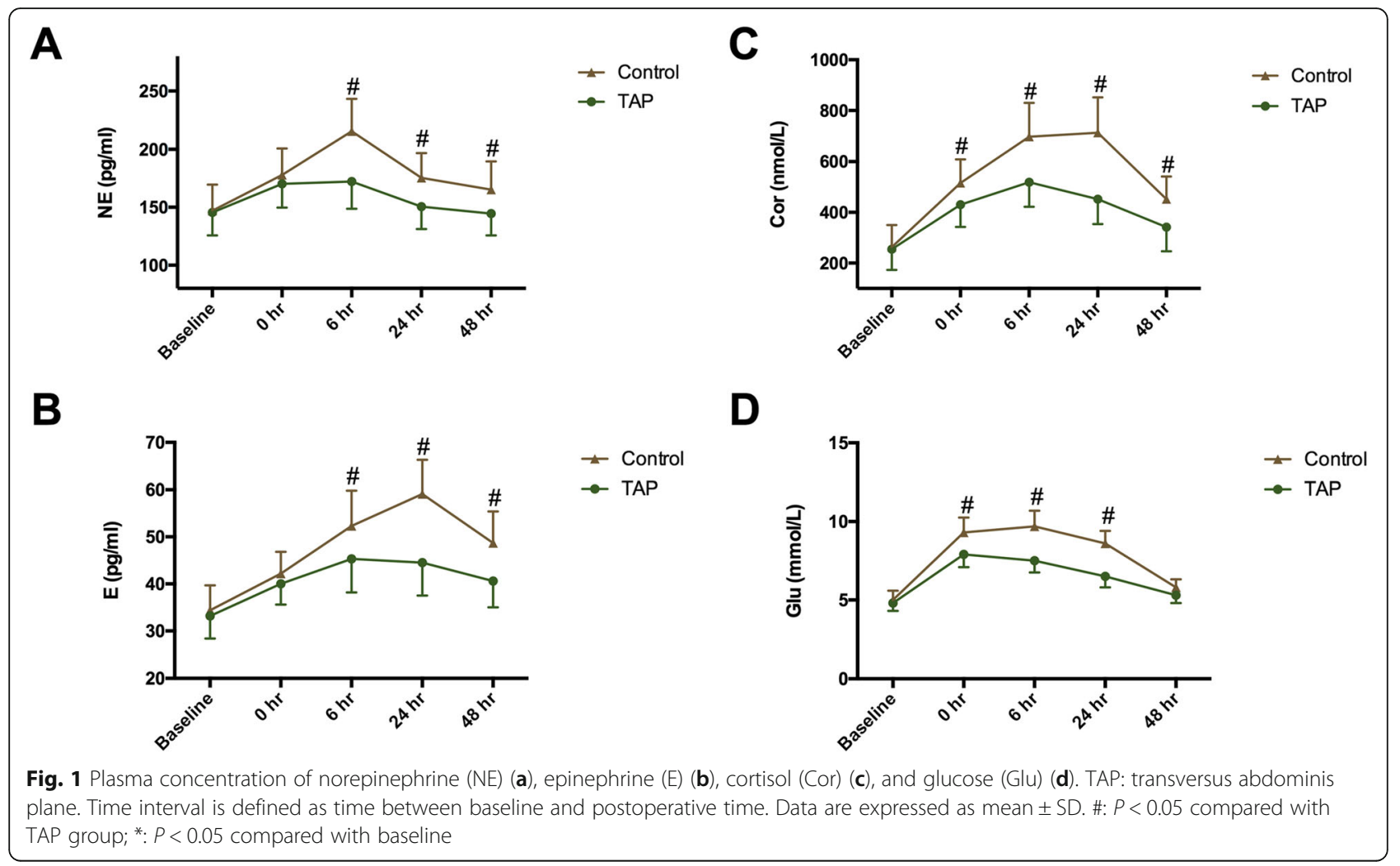

groups they peaked at $24 \mathrm{~h}$ postoperatively and then decreased (Fig. 2a, b). The IL-6 level was significantly lower in TAP group compared with in control group at $6 \mathrm{~h}(P=0.0040)$, $24 \mathrm{~h}(P<0.0001)$, and $48 \mathrm{~h}$ postoperatively $(P<0.001)$ (Fig. $2 \mathrm{a})$. The IL-10 level was higher in the control group than in TAP group at $48 \mathrm{~h}$ postoperatively $(P<0.001)$ (Fig. 2b). Ratio of IL-6/IL-10 markedly greater in control group than in TAP group at postoperative $6 \mathrm{~h}, 24 \mathrm{~h}$, and $48 \mathrm{~h}$ (all $\mathrm{P}<0.001$ ) (Fig. 2c).

Pain scores for different time points are presented in Table 2. TAP group showed lower VAS scores at postoperative $1 \mathrm{~h}, 6 \mathrm{~h}$, and $12 \mathrm{~h}$ whether the patients at rest or on movement. Whereas, no significant difference of VAS scores was found between TAP and control groups at postoperative $24 \mathrm{~h}$ and $48 \mathrm{~h}$ at rest. Hemodynamic data are shown in Fig. 3. In the control group, HR and MAP were higher at the incision time point relative to baseline and the TAP group $\left(\mathrm{P}_{\mathrm{HR}}=0.003, \mathrm{P}_{\mathrm{HR}}=0.001 ; \mathrm{P}_{\mathrm{MAP}}=\right.$ $\left.0.002, \mathrm{P}_{\text {MAP }}=0.001\right)$. In TAP group, $\mathrm{HR}$ and MAP showed no significant difference relative to baseline except for induction and intubation time point.

Consumption of intraoperative sufentanil and postoperative morphine in TAP was significantly less compared with that in the control group (all $P<0.001$ ) (Table 3 ). In control group 16 patients experienced sedation while in TAP group eight cases experienced. Additionally, patients in control group showed longer PACU stays, and hospital stays compared with TAP group. For time to first flatus, nausea, and vomit, no significant difference was identified between the two groups (Table 3).

\section{Discussion}

In this prospective, randomized trial, we found that the levels of NE, E, Cor, and Glu were blunt by TAP block during the perioperative period. Additionally, the levels of IL-6 and IL-10 were lower in TAP group significantly. Moreover, TAP block could efficiently relieve postoperative acute pain up to $12 \mathrm{~h}$ postoperatively with more stable perioperative hemodynamics compared with control group. Thus, TAP block can be used as an adjunct to general anesthesia to suppress stress responses and control pain in open radical gastrectomy surgery.

Perioperative stress response could be accurately indicated by changes of neuroendocrine mediators and cytokines via direct activation of the somatic and sympathetic nervous systems. It is well known that epidural block could block the sympathetic response and efficiently block the plasma levels of cortisol and relevant cytokines in patients [14-16]. TAP block is another method of pre-analgesic techniques. The anterior branches of spinal nerves T7-L1, running through the transversus abdominis plane, dominate the sensation of skin, muscle and parietal peritoneum $[6,17]$, which could be interdicted by wide-range TAP block. Subcostal TAP blocks afferent neural input and reduces central sensitization, which is consistent with the fact that local anesthetics inhibit both non-nociceptive and 


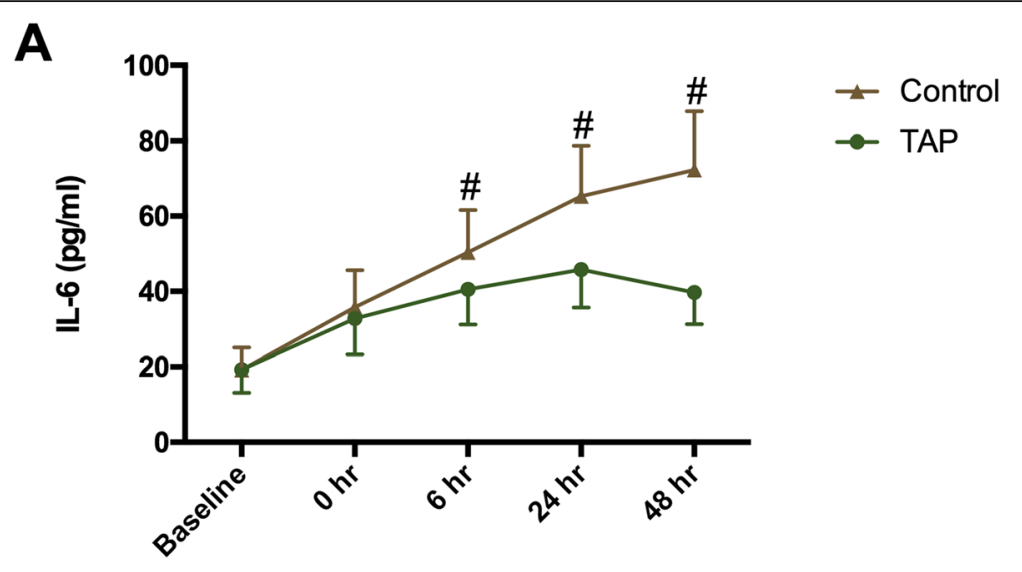

B
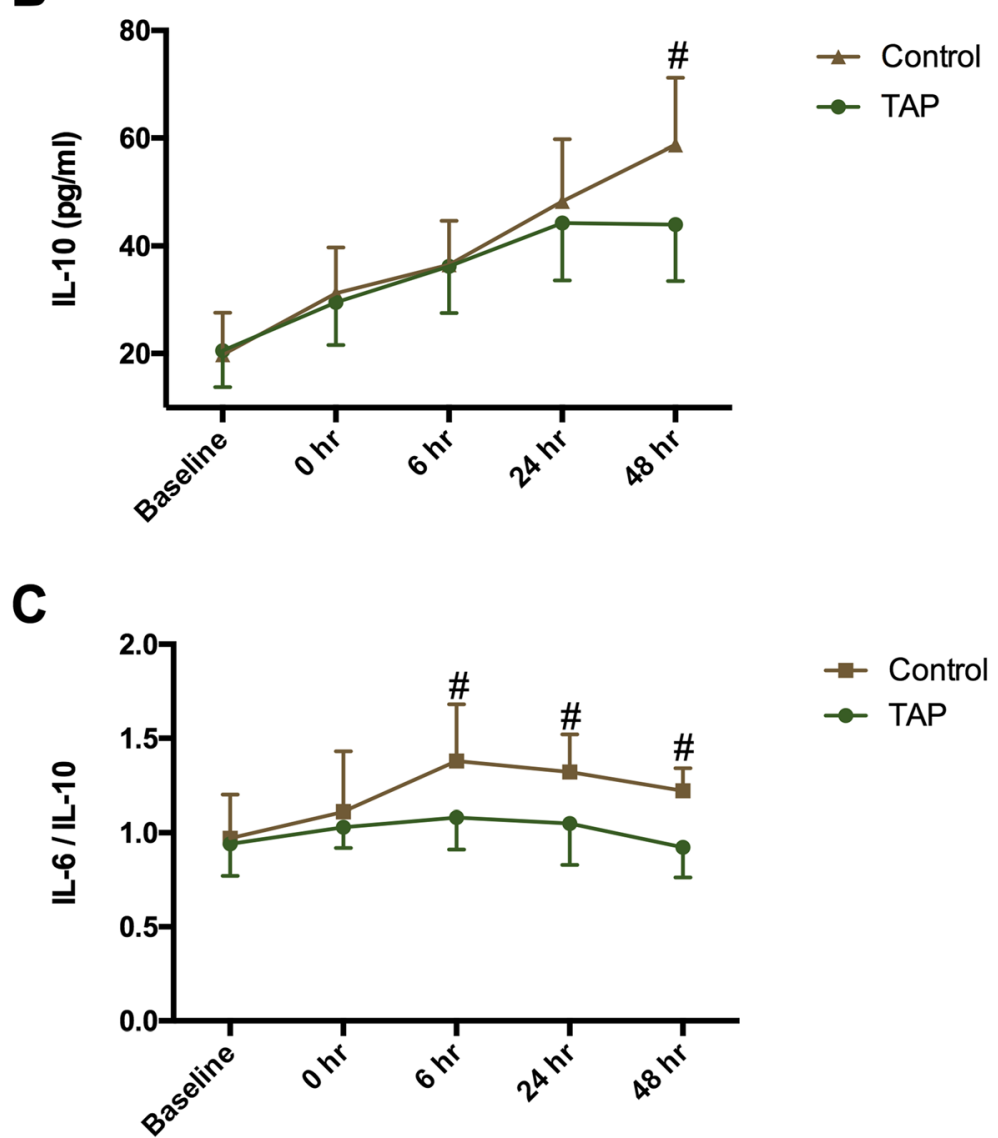

Fig. 2 Serum concentration of interleukin (IL)-6 (a), IL-10 (b), and ratio of IL-6/IL-10 (c). TAP: transversus abdominis plane. Time interval is defined as time between baseline and postoperative time. Data are expressed as mean $\pm \mathrm{SD}$. \#: P<0.05 compared with TAP group; *: $P<0.05$ compared with baseline

nociceptive stimuli. It has been reported that reported that there is a more stable level of cortisol in patients undergoing laparoscopic hysterectomy combined with TAP block than without TAP block [18]. Moreover, a case report indicated that TAP block efficiently ameliorated the stress response of a six-year-old boy who suffered from Wolf-
Hirschhorn syndrome [19]. Mohamed et al. [20] reported that TAP block was effective to decrease blood glucose level in children. In this study, TAP block reduced the levels of NE, E, Cor, and glucose significantly.

Surgical trauma and perioperative pain initiate neuroendocrine response, and stimulate the release of cytokines. 
Table 2 Visual Analog Scale Pain scores by study group

\begin{tabular}{clll}
\hline & $\begin{array}{l}\text { TAP group } \\
n=30\end{array}$ & $\begin{array}{l}\text { Control group } \\
N=31\end{array}$ & $P$-value \\
\hline At rest & & & \\
$1 \mathrm{~h}$ & $2.2 \pm 0.9$ & $2.9 \pm 0.9$ & 0.017 \\
$6 \mathrm{~h}$ & $2.2 \pm 1.0$ & $2.9 \pm 1.0$ & 0.045 \\
$12 \mathrm{~h}$ & $2.1 \pm 0.9$ & $2.7 \pm 1.2$ & 0.008 \\
$24 \mathrm{~h}$ & $2.2 \pm 1.0$ & $2.7 \pm 1.0$ & 0.175 \\
$48 \mathrm{~h}$ & $1.0 \pm 0.8$ & $1.2 \pm 0.8$ & 0.417 \\
On movement & & & \\
$1 \mathrm{~h}$ & $2.7 \pm 1.2$ & $4.3 \pm 0.8$ & $<0.001$ \\
$6 \mathrm{~h}$ & $2.9 \pm 0.7$ & $4.2 \pm 0.7$ & $<0.001$ \\
$12 \mathrm{~h}$ & $3.3 \pm 0.5$ & $4.3 \pm 1.0$ & 0.001 \\
$24 \mathrm{~h}$ & $4.1 \pm 0.6$ & $4.6 \pm 0.8$ & 0.016 \\
$48 \mathrm{~h}$ & $4.2 \pm 0.8$ & $4.5 \pm 0.9$ & 0.008 \\
\hline
\end{tabular}

Data are presented as mean \pm SD

The pro- and anti-inflammatory cytokines are crucial for acute-phase immune response after surgery. Wind et al. [21] have showed that the concentration of circulating tumor cells is the highest after the onset of surgery. Thus, the stability of immune function is essential for patients with malignant disease. IL-6, as a pro-inflammatory cytokine, induces the synthesis of CRP and other acute phase proteins within adult stem cells. Plasma level of IL- 6 is reportedly related to the severity of surgical trauma [22] and closely associated with immune status. In contrast, IL-10 is involved in immunomodulation and acts as an anti-inflammatory cytokine, which could cause systemic suppression of antitumor immunity [23]. Over the past years, the anti-inflammatory effects of local anesthetic have been extensively studied [24]. The regional anesthetic technique has been reported to reduce the cytokines and attenuate perioperative immunosuppression $[25,26]$. Importantly, some retrospective studies have showed that local anesthetic had a potential benefit in patients undergoing cancer surgery [27, 28]. In our study, TAP block significantly inhibited the release of IL-6 and IL-10, whereas the levels of IL- 6 and IL-10 continued increasing in the control group. Additionally, study has reported that IL-6/IL-10 is potentially related to an inflammatory poor prognosis [29]. Our results showed that the ratio (IL-6/IL-10) in control group was greater than that in TAP group during

\section{A}

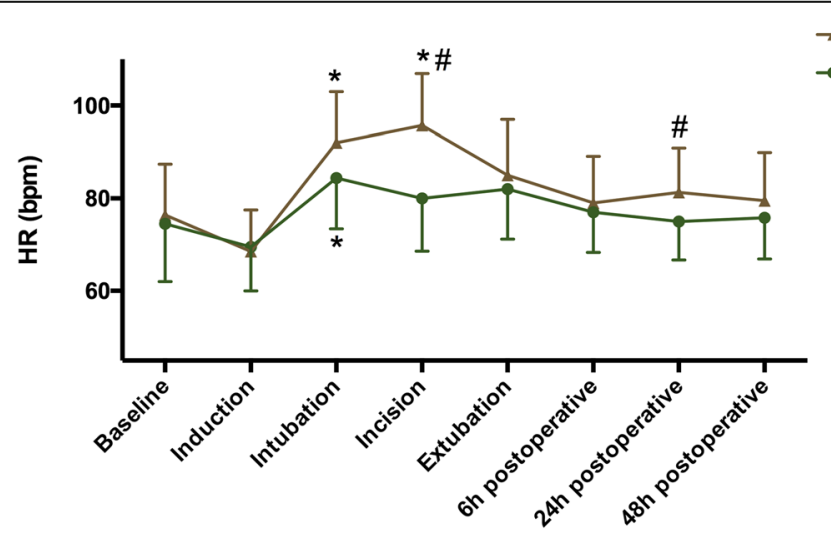

B

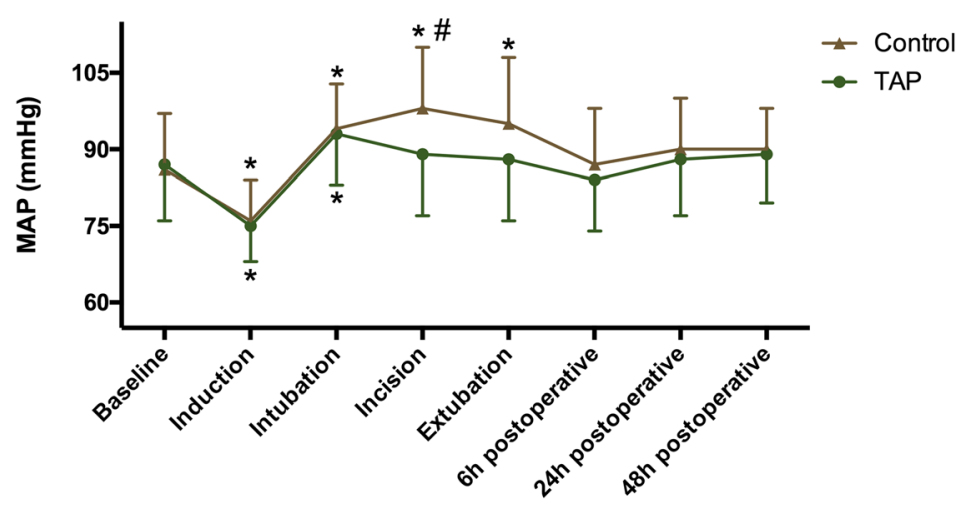

Fig. 3 Hemodynamic changes during operation and 2 days postoperatively. a heart rate (HR); $\mathbf{b}$ mean arterial blood pressure (MAP). TAP: transversus abdominis plane. Data are expressed as mean \pm SD. \#: $P<0.05$ compared with TAP group; ${ }^{*} P<0.05$ compared with baseline 
Table 3 Doses of sufentanil, ephedrine, and nicardipine and recovery time

\begin{tabular}{|c|c|c|c|}
\hline & $\begin{array}{l}\text { Group TAP } \\
n=30\end{array}$ & $\begin{array}{l}\text { Group Control } \\
N=31\end{array}$ & P-value \\
\hline \multicolumn{4}{|l|}{ Opium consumption } \\
\hline $\begin{array}{l}\text { Intraoperative } \\
\text { superaddition } \\
\text { of sufentanil }(\mu \mathrm{g})\end{array}$ & $4.3 \pm 1.5$ & $10.2 \pm 2.8$ & $<0.001$ \\
\hline $\begin{array}{l}\text { Postoperative } \\
\text { morphine } \\
\text { consumption (mg) }\end{array}$ & $46.6 \pm 8.4$ & $66.8 \pm 10.9$ & $<0.001$ \\
\hline $\begin{array}{l}\text { Patients requiring } \\
\text { ephedrine, } \mathrm{n}(\%)\end{array}$ & $2,(6.7 \%)$ & 1, (3.2\%) & 0.976 \\
\hline $\begin{array}{l}\text { Time to first } \\
\text { flatus ( } h \text { ) }\end{array}$ & $77.6 \pm 10.4$ & $81.6 \pm 10.4$ & 0.131 \\
\hline PACU stay, (min) & $44.2 \pm 7.9$ & $54.5 \pm 8.2$ & $<0.001$ \\
\hline \multicolumn{4}{|l|}{$\begin{array}{l}\text { Incidence of } \\
\text { opium-related } \\
\text { side effects, n(\%) }\end{array}$} \\
\hline Sedation & $8,(26.7 \%)$ & $16,(51.6 \%)$ & 0.046 \\
\hline Nausea & $5,(16.7 \%)$ & $6,(19.4 \%)$ & 0.785 \\
\hline Vomiting & $0,(0 \%)$ & 1, (3.2\%) & 0.987 \\
\hline Long hospitalization, n(\%) & $5,(16.7 \%)$ & $13,(41.9 \%)$ & 0.031 \\
\hline
\end{tabular}

Data are presented as mean \pm SD or number;

Criteria for out of PACU: Aldrete scores $\geq 9$;

Long hospitalization is defined as postoperative time $\geq 7$ days

postoperative $48 \mathrm{~h}$. Therefore, TAP block partially attenuated surgical trauma and maintained stable cytokine levels among patients who underwent open radical gastrectomy.

Efficient analgesia of TAP block has been well documented in human studies. Recent Meta-analyses have suggested that TAP block improves postoperative pain at both rest and movement up to $24 \mathrm{~h}$ postoperatively independent of the surgery types [30, 31]. In a prospective study, Niraj et al. [7] revealed that continuous TAP block could provide efficient analgesia for 8 to $72 \mathrm{~h}$ comparable to epidural block. In consistent with that study, our results showed that the analgesic efficacy of single-injection subcostal TAP block lasted for 12 to $16 \mathrm{~h}$. Previous study reported that TAP block has more advantages for high-risk patients with cardiovascular systemic disease due to its better intraoperative hemodynamic stability [32]. Currently, the concept of the enhanced recovery after surgery has been widely addressed. Zafar et al. [33] reported that TAP block allowed an accelerated recovery before a $48 \mathrm{~h}$ scheduled removal of the epidural catheter. Joanne et al. [34] reported that using TAP block, a $23 \mathrm{~h}$ hospital stay became a realistic goal after laparoscopic colorectal resection. Similarly, our study revealed that the hospital stays significantly decreased in TAP group, which supported a trend towards decreasing hospital stay with regional blockade.

\section{Limitations}

There were some limitations in our study. First, we only enrolled patients who underwent elective open radical gastrectomy and met the inclusion criteria, which limited the external generalizability of our results. Second, we used sufentanil for analgesia, known to affect the neuroimmunoendocrine network, which may influence our results. Third, patients in control group were not given subcostal TAP block with placebo, thus our study may be an open randomized controlled trial. Fourth, different anesthetic and antalgic medications may have complex effects on the prognosis of patient, in terms of postoperative recuperation, cancer migration, invasion, and interference with immune system, but we did not evaluate the long-term clinical effects on these individuals. Therefore, our findings are preliminary and a more comprehensive trial that assesses the long-term functional outcomes is necessary.

\section{Conclusions}

In conclusion, subcostal TAP block could inhibit the undesirable stress response and provide efficient analgesia without increasing the adverse reactions for open radical gastrectomy. For patients with malignant tumor, the relationship between reduction in stress response and long-term clinical outcomes needs to be further studied. 


\section{Supplementary information}

Supplementary information accompanies this paper at https://doi.org/10. 1186/s12871-019-0861-0.

Additional file 1. Figure S1. The flow chart of this study.

\section{Abbreviations}

ASA: American Society of Anesthesiologists; Cor: Cortisol; E: Epinephrine; Glu: Glucose; HR: Heart rate; IL: Interleukin; NE: Norepinephrine; PACU: Postanesthesia care unit; PCA: Patient-controlled analgesia; TAP: Transversus abdominis plane

\section{Acknowledgements}

None.

\section{Authors' contributions}

Conception and design of the research: RL Acquisition of data: HQ Analysis and interpretation of data: MW Statistical analysis: MW Obtaining funding: GZ Drafting the manuscript: RL Revision of manuscript for important intellectual content: KL, GZ. All authors have read and approved the manuscript.

\section{Funding}

This work was supported by Natural Science Foundation of Jilin Province (grant number 3D515B173430 and 3D516P883430).

\section{Availability of data and materials}

The data used to support the findings of this study are available from the corresponding author upon request.

\section{Ethics approval and consent to participate}

The study was approved by the Medical Ethics Committee of China-Japan Union Hospital of Jilin University (2016ks008). Written informed consents were obtained from all patients or their parents.

\section{Competing interests}

The authors declare that they have no competing interest.

\section{Author details}

${ }^{1}$ Department of Anesthesiology, China-Japan Union Hospital of Jilin University, No. 126 Xiantai Road, Changchun 130000, Jilin Province, China. ${ }^{2}$ Department of Plastic Surgery, China-Japan Union Hospital of Jilin University, Changchun 130000, Jilin Province, China. ${ }^{3}$ Department of Cardiology, No. 965 Hospital of PLA, Jilin 132000, Jilin Province, China.

Received: 24 June 2019 Accepted: 30 September 2019

Published online: 07 November 2019

\section{References}

1. Long AJ, Burton PR, De Veer MJ, Ooi GJ, Laurie CP, Nottle PD, Watt MJ, Brown WA. Radical gastric cancer surgery results in widespread upregulation of pro-tumourigenic intraperitoneal cytokines. ANZ J Surg. 2018;88(5):E370-6.

2. Desborough JP. The stress response to trauma and surgery. $\mathrm{Br} J$ Anaesth. 2000;85(1):109-17.

3. Li K, Li L, Gao M, Zhu Z, Chen P, Yang L, Zhao G. Application of ultrasoundguided subcostal transversus abdominis plane block in gastric cancer patients undergoing open gastrectomy. Int J Clin Exp Med. 2015:8(8):13976.

4. Brodner G, Van Aken H, Hertle L, Fobker M, Von Eckardstein A, Goeters C, Buerkle $\mathrm{H}$, Harks A, Kehlet $\mathrm{H}$. Multimodal perioperative management-combining thoracic epidural analgesia, forced mobilization, and oral nutrition-reduces hormonal and metabolic stress and improves convalescence after major urologic surgery. Anesth Analg. 2001;92(6):1594-600.

5. Holte K, Kehlet H. Epidural anaesthesia and analgesia - effects on surgical stress responses and implications for postoperative nutrition, Clinical nutrition (Edinburgh, Scotland). 2002;21(3):199-206.

6. Rafi AN. Abdominal field block: a new approach via the lumbar triangle. Anaesthesia. 2001;56(10):1024-6.

7. Niraj G, Kelkar A, Jeyapalan I, Graff-Baker P, Williams O, Darbar A Maheshwaran A, Powell R. Comparison of analgesic efficacy of subcostal transversus abdominis plane blocks with epidural analgesia following upper abdominal surgery. Anaesthesia. 2011;66(6):465-71.

8. Tolchard S, Davies R, Martindale S. Efficacy of the subcostal transversus abdominis plane block in laparoscopic cholecystectomy: comparison with conventional portsite infiltration. J Anaesthesiol Clin Pharmacol. 2012;28(3):339-43.

9. Wu Y, Liu F, Tang H, Wang Q, Chen L, Wu H, Zhang X, Miao J, Zhu M, Hu C, et al. The analgesic efficacy of subcostal transversus abdominis plane block compared with thoracic epidural analgesia and intravenous opioid analgesia after radical gastrectomy. Anesth Analg. 2013;117(2):507-13.

10. Kissin I. Preemptive analgesia. Anesthesiology. 2000;93(4):1138-43.

11. Milan Z, Tabor D, McConnell P, Pickering J, Kocarev M, du Feu F, Barton S. Three different approaches to transversus abdominis planeblock: a cadaveric study. Med Glas. 2011:8(2):181-4.

12. Hebbard PD, Barrington MJ, Vasey C. Ultrasound-guided continuous oblique subcostal transversus abdominis plane blockade: description of anatomy and clinical technique. Reg Anesth Pain Med. 2010;35(5):436-41.

13. Lee TH, Barrington MJ, Tran TM, Wong D, Hebbard PD. Comparison of extent of sensory block following posterior and subcostal approaches to ultrasound-guided transversus abdominis plane block. Anaesth Intensive Care. 2010;38(3):452-60.

14. Aono H, Takeda A, Tarver SD, Goto H. Stress responses in three different anesthetic techniques for carbon dioxide laparoscopic cholecystectomy. J Clin Anesth. 1998;10(7):546-50.

15. Li Y, Wang B, Zhang LL, He SF, Hu XW, Wong GT, Zhang Y. Dexmedetomidine combined with general anesthesia provides similar intraoperative stress response reduction when compared with a combined general and epidural anesthetic technique. Anesth Analg. 2016;122(4):1202-10.

16. Li Y, Zhu S, Yan M: Combined general/epidural anesthesia (ropivacaine 0. $375 \%$ ) versus general anesthesia for upper abdominal surgery. Anesthesia and analgesia 2008, 106(5):1562-1565, table of contents.

17. Findlay JM, Ashraf SQ, Congahan P. Transversus abdominis plane (TAP) blocks-a review. Surgeon. 2012;10(6):361-7.

18. Yuanc W, Aij Y: Effect of transversus abdominis plane block on cortisol after laparoscopic hysterectomy (in Chinese with English abstract). J Qiqijaer medical college 2014, 35:945-950.

19. Kondo S, Okuyama K, Ikemoto K, Furuya A, Matsukawa T: [General anesthesia for a boy with wolf-Hirschhorn syndrome]. Masui 2013, 62(12): 1466-1468.

20. Abu Elyazed MM, Mostafa SF, Abdullah MA, Eid GM. The effect of ultrasound-guided transversus abdominis plane (TAP) block on postoperative analgesia and neuroendocrine stress response in pediatric patients undergoing elective open inguinal hernia repair. Paediatr Anaesth. 2016;26(12):1165-71.

21. Wind J, Tuynman JB, Tibbe AG, Swennenhuis JF, Richel DJ, van Berge Henegouwen MI, Bemelman WA. Circulating tumour cells during laparoscopic and open surgery for primary colonic cancer in portal and peripheral blood. Eur J Surg Oncol. 2009:35(9):942-50.

22. Cruickshank AM, Fraser WD, Burns HJ, Van Damme J, Shenkin A. Response of serum interleukin-6 in patients undergoing elective surgery of varying severity. Clinical science (London, England: 1979). 1990;79(2):161-5.

23. Seo N, Hayakawa S, Takigawa M, Tokura Y. Interleukin-10 expressed at early tumour sites induces subsequent generation of CD4(+) T-regulatory cells and systemic collapse of antitumour immunity. Immunology. 2001;103(4):449-57.

24. Hollmann MW, Durieux ME. Local anesthetics and the inflammatory response: a new therapeutic indication? Anesthesiology. 2000:93(3):858-75.

25. Deegan CA, Murray D, Doran P, Moriarty DC, Sessler DI, Mascha E, Kavanagh $\mathrm{BP}$, Buggy DJ. Anesthetic technique and the cytokine and matrix metalloproteinase response to primary breast cancer surgery. Reg Anesth Pain Med. 2010;35(6):490-5.

26. Sultan SS. Paravertebral block can attenuate cytokine response when it replaces general anesthesia for cancer breast surgeries. Saudi J Anaesth. 2013;7(4):373-7.

27. Biki B, Mascha E, Moriarty DC, Fitzpatrick JM, Sessler DI, Buggy DJ. Anesthetic technique for radical prostatectomy surgery affects cancer recurrence: a retrospective analysis. Anesthesiology. 2008;109(2):180-7.

28. Christopherson R, James KE, Tableman M, Marshall P, Johnson FE. Longterm survival after colon cancer surgery: a variation associated with choice of anesthesia. Anesth Analg. 2008;107(1):325-32.

29. Weis F, Beiras-Fernandez A, Schelling G, Briegel J, Lang P, Hauer D, Kreth S, Kaufmann I, Lamm P, Kilger E. Stress doses of hydrocortisone in high-risk patients undergoing cardiac surgery: effects on interleukin- 6 to interleukin10 ratio and early outcome. Crit Care Med. 2009;37(5):1685-90. 
30. Baeriswyl M, Kirkham KR, Kern C, Albrecht E. The analgesic efficacy of ultrasound-guided transversus abdominis plane block in adult patients: a meta-analysis. Anesth Analg. 2015;121(6):1640-54.

31. Champaneria R, Shah L, Geoghegan J, Gupta JK, Daniels JP. Analgesic effectiveness of transversus abdominis plane blocks after hysterectomy: a meta-analysis. Eur J Obstet Gynecol Reprod Biol. 2013;166(1):1-9.

32. Tsuchiya M, Takahashi R, Furukawa A, Suehiro K, Mizutani K, Nishikawa K. Transversus abdominis plane block in combination with general anesthesia provides better intraoperative hemodynamic control and quicker recovery than general anesthesia alone in high-risk abdominal surgery patients. Minerva Anestesiol. 2012;78(11):1241-7.

33. Zafar N, Davies R, Greenslade GL, Dixon AR. The evolution of analgesia in an 'accelerated' recovery programme for resectional laparoscopic colorectal surgery with anastomosis. Colorectal Dis. 2010;12(2):119-24.

34. Favuzza J, Brady K, Delaney CP. Transversus abdominis plane blocks and enhanced recovery pathways: making the 23-h hospital stay a realistic goal after laparoscopic colorectal surgery. Surg Endosc. 2013;27(7):2481-6.

\section{Publisher's Note}

Springer Nature remains neutral with regard to jurisdictional claims in published maps and institutional affiliations.

Ready to submit your research? Choose BMC and benefit from:

- fast, convenient online submission

- thorough peer review by experienced researchers in your field

- rapid publication on acceptance

- support for research data, including large and complex data types

- gold Open Access which fosters wider collaboration and increased citations

- maximum visibility for your research: over $100 \mathrm{M}$ website views per year

At BMC, research is always in progress.

Learn more biomedcentral.com/submissions 